\title{
Five-year effects of nasal continuous positive airway pressure in obstructive sleep apnoea syndrome
}

\author{
A. Chaouat, E. Weitzenblum, R. Kessler, M. Oswald, E. Sforza, \\ M-N. Liegeon, J. Krieger
}

\begin{abstract}
Five-year effects of nasal continuous positive airway pressure in obstructive sleep apnoea syndrome. A. Chaouat, E. Weitzenblum, R. Kessler, M. Oswald, E. Sforza, MN. Liegeon, J. Krieger. C ERS Journals Ltd 1997.

ABSTRACT: There have been very few studies assessing the long-term physiological effects of nasal continuous positive airway pressure (CPAP) for the obstructive sleep apnoea syndrome. We therefore investigated prospectively the evolution of lung function, arterial blood gases and pulmonary haemodynamics in patients with this syndrome treated with CPAP. Sixty five patients were included. The mean duration of home treatment with nasal CPAP was $64 \pm 6$ months. Most of the patients $(77 \%)$ were smokers at the baseline assessment.

We observed a small, but significant, decrease in forced expiratory volume in one second (FEV1) from $80 \pm 21 \%$ at baseline (to) to $76 \pm 21 \%$ of the predicted value at the follow-up evaluation $(t 5)(\mathrm{p}<0.01)$. Arterial oxygen tension $\left(\mathrm{Pa}_{\mathrm{a}} \mathrm{O}_{2}\right)$ for the group as a whole remained stable $(9.4 \pm 1.5 \mathrm{kPa}(71 \pm 11 \mathrm{mmHg})$ versus $9.4 \pm 1.2 \mathrm{kPa}$ $(71 \pm 9 \mathrm{mmHg}))$. However, $\mathrm{Pa}_{\mathrm{a}} \mathrm{O}_{2}$ increased in the subgroup of patients with hypoxaemia at $t 0(\mathrm{n}=23)$, from $7.8 \pm 0.7 \mathrm{kPa}(59 \pm 5 \mathrm{mmHg})$ to $8.9 \pm 1.2 \mathrm{kPa}(67 \pm 9 \mathrm{mmHg})$. Arterial carbon dioxide tension $\left(\mathrm{Pa}_{\mathrm{a}}, \mathrm{CO}_{2}\right)$ for the group as a whole increased slightly, but significantly, from $5.2 \pm 0.7 \mathrm{kPa}(39 \pm 5 \mathrm{mmHg})$ to $5.4 \pm 0.5 \mathrm{kPa}(41 \pm 4 \mathrm{mmHg})$ $(\mathbf{p}<0.05)$. Mean pulmonary artery pressure $\left(\bar{P}_{\text {pa }}\right)$ at rest did not change $(16 \pm 5$ mmHg versus $17 \pm 5 \mathrm{mmHg}$; Ns) nor did exercising $\bar{P}_{\text {pa. }}$. In the 11 patients with pulmonary hypertension at $t 0, \bar{P}$ pa was $24 \pm 5 \mathrm{mmHg}$ at $t 0$ versus $20 \pm 7 \mathrm{mmHg}$ at $t 5$ (Ns).

We conclude that the significant decrease of forced expiratory volume in one second after 5 yr follow-up was related to a high percentage of smokers and exsmokers in the study population. Daytime arterial oxygen tension and pulmonary artery pressure remained stable in an unselected series of 65 obstructive sleep apnoea syndrome patients treated for 5 yrs with nasal continuous positive airway pressure, unlike arterial carbon dioxide tension, which increased by a small, but significant, amount.
\end{abstract}

Eur Respir J 1997; 10: 2578-2582.

Since the original publication by Sullivan et al. [1], there has been considerable development of treatment with nasal continuous positive airway pressure (CPAP) in patients with the obstructive sleep apnoea syndrome (OSAS). However, there have been very few studies devoted to the long-term physiological effects of this treatment [2-4].

The evolution of lung function and arterial blood gases, particularly in those patients who are hypoxaemic, hypercapnic and have pulmonary hypertension at the beginning of treatment with nasal CPAP is not well appreciated. In 1990 we reported that nasal CPAP improved hypoxaemia and hypercapnia [2]. The same study also showed that pulmonary haemodynamics did not change in these patients. However, the duration of follow-up was limited to a mean of 18 months, whereas at the time of the present study some patients have been receiving treatment for more than $10 \mathrm{yrs}$.

Thus, the aim of the present study was to investigate prospectively the evolution of lung function, arterial blood gases and pulmonary haemodynamics in a series of unselected obstructive sleep apnoea patients who
Dept of Respiratory Medicine and Sleep Disorders Unit, University Hospital Strasbourg, France.

\author{
Correspondence: A. Chaouat \\ Service de Pneumologie \\ Hôpital de Hautepierre \\ Avenue Molière \\ 67098 Strasbourg Cedex \\ France
}

Keywords:

Continuous positive airway pressure

hypercapnia

hypoxaemia

pulmonary hypertension

sleep apnoea syndrome

Received: January 171997

Accepted after revision July 51997 were followed for 5 yrs. No similar study has been reported beyond a follow-up of 18 months.

\section{Patients and methods}

The eligible population consisted of patients referred to our Sleep Disorders Unit with a suspected diagnosis of OSAS. The inclusion criteria were the polysomnographic demonstration of 20 or more apnoeas plus hypopnoeas per hour of sleep ( $>80 \%$ of them being of obstructive type) and the acceptance of home treatment with nasal CPAP. Spirometry and arterial blood gas measurements were performed in all patients before starting nasal CPAP. Patients were asked to undergo right heart catheterization provided that there was no contra-indication. After approximately 5 yrs (range 60-71 months) of home treatment with nasal CPAP, all patients underwent follow-up evaluation including spirometry and arterial blood gas measurement. Right heart catheterization after 5 yrs of follow-up was proposed to patients who underwent it initially. All catheterized patients gave 
informed consent. Investigation was not performed during an acute exacerbation of respiratory disease (pulmonary infection, acute bronchitis, episode of right heart failure or acute respiratory failure) and the time between any such episode and the day of investigation was at least 6 weeks.

Polysomnography was performed during two consecutive nights, without (diagnostic night) and with CPAP, as part of the baseline evaluation. The method has been described elsewhere [2]. Briefly, the polygraphic sleep recording included standard electro-encephalograph, electro-oculograph, and electromyograph of chin muscles. Breathing during sleep was analysed with a Fleisch No. 2 pneumotachograph (Godart, Statham Instruments, Oxnard, CA, USA) attached to a soft Silastic facial mask (No. 3434, Bird Corp, Palm Springs, CA, USA), and by means of either thoracic and abdominal mercury-filled strain gauges or an oesophageal balloon. Transcutaneous oxygen saturation was recorded with a pulse oximeter (Biox III, Ohmeda, Louisville, CO, USA). Central, obstructive and mixed apnoeas were defined according to usual criteria [5]. Hypopnoeas were defined as a $50 \%$ fall of tidal volume from its value during quiet wakefulness, for at least $10 \mathrm{~s}$, without a major change in respiratory rate.

Conventional spirometry was performed with a $10 \mathrm{~L}$ closed-circuit spirograph. Static lung volumes were measured by the closed-circuit helium dilution method. Reference values were those of the European Respiratory Society [6].

Right heart catheterization was performed as previously described [7]. Briefly, the haemodynamic measurements were always done while the patient was awake, in the supine position. For the purpose of this study we used small diameter floated catheters, either Grandjean flexopulmocaths (French size No. 4; Plastimed, SaintLeu-la-Forêt, France) or Swan-Ganz catheters (French size No. 5; Edwards Lab Inc, Anasco, Puerto Rico). The catheter was introduced percutaneously into an antecubital or femoral vein. Arterial blood gases were measured simultaneously via a Cournand needle inserted into the brachial artery. An $8 \mathrm{~min}$ period of steady-state exercise on a bicycle-ergometer in the supine position was performed when the patient's condition allowed it. The load was $40 \mathrm{~W}$.

During the second night of the baseline polysomnography, CPAP was applied in all patients via a nasal mask using a commercial device (Pression Plus; SEFAM, Vandoeuvre-les-Nancy, France). The level of nasal CPAP was rapidly increased above the starting level of $2 \mathrm{cmH}_{2} \mathrm{O}$ until apnoeas and snoring were abolished. The pressure reached ranged $4-14 \mathrm{cmH}_{2} \mathrm{O}$. Patients who had persistent nocturnal hypoxaemia in spite of nasal CPAP were treated concomitantly with nocturnal oxygen therapy to achieve an arterial oxygen saturation $\left(\mathrm{S}_{\mathrm{a}}, \mathrm{O}_{2}\right)$ above 90\% throughout the night. Home treatment with nasal CPAP was initiated approximately 1 week after the baseline evaluation. The level of CPAP was adjusted if necessary during a second polysomnographic study performed after $1 \mathrm{yr}$ of follow-up. The rate of use of CPAP was measured by the time counter built into the CPAP device. The difference in the time counter readings divided by the duration of treatment was used as an estimate of the mean daily use of CPAP.

\section{Statistical analysis}

Values were expressed as the mean \pm SD. Groups of patients were compared using Mann-Whitney U-test. Baseline $(t 0)$ and follow-up ( $t 5)$ values were compared using Student's paired t-test or Wilcoxon rank sum test when the number of pairs was less than 30 . Rejection of the null hypothesis required a p-value of less than 0.05 .

\section{Results}

Between December 1983 and June 1989, 107 patients met the criteria of the present study. During the followup, 10 patients died, 29 patients stopped nasal CPAP and three decided to be treated elsewhere. Therefore 65 patients (63 males and two females) were re-evaluated after 5 yrs of home treatment with nasal CPAP. Among these 65 patients, 62 underwent a pulmonary haemodynamic study at $t 0$. Unfortunately, only 44 patients accepted a pulmonary haemodynamic study at $t 5$. Thus, pulmonary artery pressures were compared in 44 patients. Age, lung function, arterial blood gases, sleep parameters and mean pulmonary artery pressure $\left(\bar{P}_{\mathrm{pa}}\right)$ at $t 0$ were similar in these 44 patients and in the others who did not undergo right heart catheterization at $t 5$ (data not shown). Pulmonary capillary wedge pressure $\left(P_{\mathrm{cw}}\right)$ was measurable in 42 patients at $t 0$, but valid measurements were obtained in only 16 patients at both $t 0$ and $t 5$. None of the 65 re-evaluated patients were treated with conventional long-term oxygen therapy $(\geq 16 \mathrm{~h}$ daily) during the follow-up. Three were treated with nocturnal oxygen therapy $(6-8 \mathrm{~h}$ night) in conjunction with nasal CPAP.

\section{Baseline evaluation ( $\mathrm{t} 0$ )}

The mean $( \pm \mathrm{SD})$ age of the 65 patients was $53 \pm 10$ yrs. Fifty $(77 \%)$ of the 65 patients were current smokers at $t 0$, of whom $27(42 \%)$ were heavy smokers $(>30$ pack yrs). The majority of patients were obese: $46(71 \%)$ had a body mass index $(\mathrm{BMI})>30 \mathrm{~kg} \cdot \mathrm{m}^{-2}$, among whom 16 $(25 \%)$ had a BMI $>35 \mathrm{~kg} \cdot \mathrm{m}^{-2}$. The mean $( \pm \mathrm{SD}) \mathrm{BMI}$ was $33 \pm 6 \mathrm{~kg} \cdot \mathrm{m}^{-2}$ at $t 0$.

The results of the baseline polysomnographic data are shown in table 1 . They show high values of apnoea and apnoea+hypopnoea index $\left(70 \pm 36\right.$ and $87 \pm 33$ events $\cdot \mathrm{h}^{-1}$, respectively). Sleep architecture was severely disturbed, with predominance of sleep stages 1 and 2 and

Table 1. - Baseline polysomnographic data in the 65 patients

\begin{tabular}{lcc}
\hline Variables & Mean & SD \\
\hline AI events $\cdot \mathrm{h}^{-1}$ & 70 & 36 \\
AHI events $\cdot \mathrm{h}^{-1}$ & 87 & 33 \\
TST min & 292 & 94 \\
$\quad$ Stages 1 and 2\% & 90 & 9 \\
Stages 3 and 4\% & 2 & 5 \\
REM \% & 8 & 6 \\
$\mathrm{~S}_{\mathrm{a}, \mathrm{O}_{2}} \%$ & 92 & 5 \\
$\mathrm{~S}_{\mathrm{a}, \mathrm{O}_{2}}<90 \% \quad \%$ & 24 & 26 \\
\hline
\end{tabular}

AI: apnoea index; AHI: apnoea+hypopnoea index; TST: total sleep time; REM: rapid eye movement; $\mathrm{S}_{\mathrm{a}, \mathrm{O}_{2}}$ : arterial oxygen saturation; $\mathrm{Sa}_{\mathrm{a}} \mathrm{O}_{2}<90 \%$ : time spent with $\mathrm{Sa}_{\mathrm{a}} \mathrm{O}_{2}<90 \%$. 
very short periods spent in stages 3 and 4 and rapid eye movement (REM) sleep.

The average value of the forced expiratory volume in one second (FEV1)/vital capacity (VC) ratio was normal $(72 \pm 10 \%)$, whereas VC, FEV1 and total lung capacity (TLC) were at the lower limit of the normal range (table 2). Thirteen (20\%) patients had an obstructive spirographic pattern, defined by a FEV $1 / \mathrm{VC}$ ratio $\leq 65 \%$. Nineteen $(29 \%)$ patients, most of whom were markedly obese, had a restrictive ventilatory defect defined as TLC $<80 \%$ pred. Four $(6 \%)$ patients had both an obstructive and a restrictive pattern.

The mean arterial oxygen tension $\left(\mathrm{Pa}_{\mathrm{a}} \mathrm{O}_{2}\right)$ for the group as a whole was mildly decreased $(9.4 \pm 1.5 \mathrm{kPa}(71 \pm 11$ $\mathrm{mmHg})$ ) (table 3$)$. Twenty three $(35 \%)$ patients were initially hypoxaemic, as defined by a $\mathrm{Pa}, \mathrm{O}_{2} \leq 8.6 \mathrm{kPa}(65$ $\mathrm{mmHg})$. The average arterial carbon dioxide tension $\left(P \mathrm{a}, \mathrm{CO}_{2}\right)$ was normal $(5.2 \pm 0.7 \mathrm{kPa}(39 \pm 5 \mathrm{mmHg}))$ and only eight of the $65(12 \%)$ patients were hypercapnic, as defined by a $P \mathrm{a}, \mathrm{CO}_{2} \geq 6.9 \mathrm{kPa}(45 \mathrm{mmHg})$.

The average value of $\bar{P}$ pa for the 44 patients who underwent a comparative pulmonary haemodynamic study was normal $(16 \pm 5 \mathrm{mmHg})$. Eleven of the $44(25 \%)$ patients had pulmonary hypertension, defined by a $\bar{P}_{\text {pa }} \geq 20$ $\mathrm{mmHg}$. When present, pulmonary hypertension was mild to moderate and $\bar{P}_{\text {pa }}$ never exceeded $35 \mathrm{mmHg}$. The average value of $P_{\mathrm{cw}}$ at $t 0$ for the 16 patients in whom it could be measured at $t 0$ and $t 5$ was $6 \pm 2 \mathrm{mmHg}$, ranging $3-16 \mathrm{mmHg}$.

Table 2. - Anthropometric data and lung function before $(t 0)$ and after 5 yrs $(t 5)$ of treatment with continuous positive airway pressure (CPAP) in 65 patients

\begin{tabular}{lcc}
\hline Variables & Baseline & Follow-up \\
$t 0$ & 35 & \\
\hline BMI $\mathrm{kg} \cdot \mathrm{m}^{-2}$ & $33 \pm 6$ & $34 \pm 6^{*}$ \\
VC mL & $3650 \pm 910$ & $3510 \pm 930^{*}$ \\
VC \% pred & $86 \pm 15$ & $85 \pm 16$ \\
FEV1 mL & $2660 \pm 860$ & $2410 \pm 820^{* * *}$ \\
FEV $\%$ pred & $80 \pm 21$ & $76 \pm 21^{* *}$ \\
FEV $1 / \mathrm{VC} \%$ & $72 \pm 10$ & $68 \pm 11^{* * *}$ \\
TLC $\mathrm{mL}$ & $5610 \pm 1190$ & $5470 \pm 1070$ \\
TLC $\%$ pred & $86 \pm 14$ & $84 \pm 13$ \\
\hline
\end{tabular}

Values are presented as mean \pm SD. BMI: body mass index; VC: vital capacity; \% pred: percentage of predicted value; FEV1: forced expiratory volume in one second; TLC: total lung capacity. $* * *, * * *: \mathrm{p}<0.05, \mathrm{p}<0.01, \mathrm{p}<0.001$ versus baseline (paired t-test).

Table 3. - Arterial blood gases and pulmonary haemodynamics before $(t 0)$ and after 5 yrs $(t 5)$ of treatment with continuous positive airway pressure (CPAP)

\begin{tabular}{lccc}
\hline Variables & $\begin{array}{c}\text { Pairs } \\
\mathrm{n}\end{array}$ & $\begin{array}{c}\text { Baseline } \\
t 0\end{array}$ & $\begin{array}{c}\text { Follow-up } \\
t 5\end{array}$ \\
\hline$P_{\mathrm{a}, \mathrm{O}_{2}} \mathrm{mmHg}$ & 65 & $71 \pm 11$ & $71 \pm 9$ \\
$\mathrm{~Pa}_{\mathrm{CO}} \mathrm{mmHg}$ & 65 & $39 \pm 5$ & $41 \pm 4^{*}$ \\
$\bar{P}_{\text {pa rest } \mathrm{mmHg}}$ & 44 & $16 \pm 5$ & $17 \pm 5$ \\
$P_{\mathrm{cw}}$ rest $\mathrm{mmHg}$ & 16 & $6 \pm 2$ & $9 \pm 3^{* *}$ \\
$\bar{P}_{\text {pa }}$ exercise $\mathrm{mmHg}$ & 34 & $30 \pm 9$ & $30 \pm 7$ \\
\hline
\end{tabular}

Values are presented as mean \pm SD. $P \mathrm{a}, \mathrm{O}_{2}$ : arterial oxygen tension; $P \mathrm{a}_{\mathrm{a}} \mathrm{CO}_{2}$ : arterial carbon dioxide tension; $\bar{P}_{\text {pa: }}$ mean pulmonary artery pressure; $P_{\mathrm{cw}}$ : pulmonary capillary wedge pressure. *,**: $\mathrm{p}<0.05, \mathrm{p}<0.01$ versus baseline (Wilcoxon or paired t-test). $1 \mathrm{mmHg}=0.133 \mathrm{kPa}$.

\section{Follow-up evaluation (t5)}

The 65 patients reported good adaptation to the CPAP equipment. The mean duration of home treatment with nasal CPAP between $t 0$ and $t 5$ was $64 \pm 6$ months. The average pressure was $10 \pm 3 \mathrm{cmH}_{2} \mathrm{O}$ during the first year of treatment and $9 \pm 2 \mathrm{cmH}_{2} \mathrm{O}$ during the remaining time. The mean daily use of CPAP from to to $t 5$ was 5.2 $\mathrm{h} \cdot$ night $^{-1}$.

Thirty of the 50 smokers at $t 0$ had stopped smoking during the follow-up. BMI increased slightly from $33 \pm$ 6 to $34 \pm 6 \mathrm{~kg} \cdot \mathrm{m}^{-2}(\mathrm{p}<0.05)$ after $5 \mathrm{yrs}$ of home treatment with nasal CPAP.

VC (\% pred) and TLC did not change significantly (table 2). Small, but significant, decreases in FEV1\% pred and $\mathrm{FEV} 1 / \mathrm{VC}$ ratio were observed. The average values of FEV1 were $2,660 \pm 860 \mathrm{~mL}$ at $t 0$ versus $2,410 \pm$ $820 \mathrm{~mL}$ at $t 5(\mathrm{p}<0.001)$ and the mean annual decrease in FEV1 was $48 \mathrm{~mL}$ with a large dispersion of indiviual values (SD $74 \mathrm{~mL}$ ). Twenty six $(40 \%)$ patients showed an obstructive spirographic pattern (as defined above) at $t 5$ versus $13(20 \%)$ at $t 0$.

$P \mathrm{a}, \mathrm{O}_{2}$ as a mean value remained stable in the 65 patients who were re-evaluated (table 3 ). However, $\mathrm{Pa}_{\mathrm{a}} \mathrm{O}_{2}$ improved significantly from $7.8 \pm 0.7 \mathrm{kPa}(59 \pm 5 \mathrm{mmHg})$ to $8.9 \pm 1.2 \mathrm{kPa}(67 \pm 9 \mathrm{mmHg})(\mathrm{p}<0.001)$ in the 23 patients who were hypoxaemic at $t 0 . \mathrm{Pa}_{\mathrm{a}} \mathrm{CO}_{2}$ increased very slightly, but significantly, from $5.2 \pm 0.7 \mathrm{kPa}(39 \pm 5 \mathrm{mmHg})$ to $5.5 \pm 0.5 \mathrm{kPa}(41 \pm 4 \mathrm{mmHg})(\mathrm{p}<0.05)$ in the group as a whole, but had a tendency to decrease from $6.4 \pm 0.4$ $\mathrm{kPa}(48 \pm 3 \mathrm{mmHg})$ to $5.9 \pm 0.5 \mathrm{kPa}(44 \pm 4 \mathrm{mmHg})(\mathrm{p}=0.09)$ in the eight patients who were hypercapnic at $t 0$.

Neither $\bar{P}$ pa at rest nor $\bar{P}_{\text {pa }}$ during exercise changed significantly (table 3 ). Concerning the 11 patients who had pulmonary hypertension at $t 0$, the average values of $\bar{P}_{\mathrm{pa}}$ at rest were $24 \pm 5 \mathrm{mmHg}$ at $t 0$ versus $20 \pm 7 \mathrm{mmHg}$ at $t 5(\mathrm{p}=0.14) . P_{\mathrm{cw}}$ as a mean increased significantly from $6 \pm 2 \mathrm{mmHg}$ to $9 \pm 3 \mathrm{mmHg}(\mathrm{p}<0.01)$ in the 16 patients in whom repeat measurements could be made.

\section{Discussion}

The present study shows that in the group of OSAS patients, including a large number of smokers, FEV1 and $\mathrm{FEV} 1 / \mathrm{VC}$ ratio decreased significantly after 5 yrs of home treatment with nasal CPAP, $\mathrm{Pa}, \mathrm{O}_{2}$ remained stable and $P \mathrm{a}, \mathrm{CO}_{2}$ increased slightly. As regards pulmonary haemodynamics, $\bar{P}_{\mathrm{pa}}$ at rest and during exercise remained unchanged.

One hundred and seven patients met all the criteria at the baseline evaluation. From these 107 patients, three chose to be treated elsewhere, 29 stopped nasal CPAP and 10 died. Consequently, 42 patients could not complete the study. Hence, overall less than $10 \%$ of patients were lost each year. This disadvantage of prospective longitudinal studies cannot be avoided [8]. Therefore, we believe that the 65 patients included in this study and re-evaluated after 5 yrs of follow-up were reasonably representative of an OSAS population seen at a sleep laboratory. This was confirmed by the similarity between these 65 patients and other series of OSAS patients, with regard to lung function, arterial blood gases and pulmonary haemodynamics $[9,10]$. 
We observed a small but significant decrease in FEV1 and $\mathrm{FEV} 1 / \mathrm{VC}$ ratio from $t 0$ to $t 5$. The decrease in FEV1 and $\mathrm{FEV} 1 / \mathrm{VC}$ ratio can be explained by the fact that there was a high percentage of smokers at the beginning of the study. For the study as a whole, FEV1 decreased from 2,660 to $2,410 \mathrm{~mL}$ during a follow-up of 5 yrs, which corresponds to a mean decrease of approximately $50 \mathrm{~mL} \cdot \mathrm{yr}^{-1}$. This is less than the annual decrease in heavy smokers "at risk" [11], but more than the functional evolution of never-smokers. In the latter, FEV1 declines by about $25-30 \mathrm{~mL} \cdot \mathrm{yr}^{-1}$ [6]. In heavy smokers, FEV1 decreases more, and different authors have observed variable degrees of worsening of the FEV1. SNIDER et al. [12] reported a decrease of $150 \mathrm{~mL} \cdot \mathrm{yr}^{-1}$ in susceptible smokers, whereas a mean decrease of $90 \mathrm{~mL} \cdot \mathrm{yr}^{-1}$ was found by Burrows [13] in COPD patients whose FEV1 was more than $45 \%$ of the predicted value. Furthermore, FLETCHER [11] reported that the accelerated decline of FEV1 in smokers usually stops with the cessation of smoking, the decrease of FEV 1 being then similar to that observed in nonsmokers. In our series, most of the patients were smokers at the beginning of the study but more than half stopped smoking. Thus, a mean decrease in FEV1 of $50 \mathrm{~mL} \cdot \mathrm{yr}^{-1}$ is similar to the expected value. In fact, we observed a similar decrease of FEV1 irrespective of smoking habits. The average annual decreases of FEV1 were $48 \pm 74 \mathrm{~mL}, 44 \pm 78 \mathrm{~mL}$ and $56 \pm$ $72 \mathrm{~mL}$ in the 15 never-smokers, 30 exsmokers and 20 current smokers at $t 5$, respectively. This discrepancy between the present results and the studies quoted above is probably due to the small number of patients in each group, subdivided according to smoking habits, and to the large dispersion of individual values.

Since smoking is a risk factor for both sleep-disordered breathing [14] and COPD, it is not surprising that we observed a high percentage of smokers and a relatively high frequency of associated COPD in our series of OSAS patients. This frequency of associated COPD increased at the follow-up evaluation as FEV1 and FEV1/ $\mathrm{VC}$ ratio declined with time, which is consistent with a cross-sectional study [15] from our department. Our previous study [15] showed that OSAS patients associated COPD were significantly older than OSAS patients without chronic airway disease. The mean ages were $58 \pm 9$ and $53 \pm 10 \mathrm{yrs}$, respectively $(\mathrm{p}=0.01)$. As a consequence, spirometric measurements should be repeated during the follow-up of OSAS patients who have abnormal or borderline values. However, the most important issue is to ensure smoking cessation in these patients. This may have clinical implications since OSAS patients with associated COPD are at a greater risk of developing respiratory insufficiency and cor pulmonale $[9,15,16]$.

In our 65 patients, $\mathrm{Pa}, \mathrm{O}_{2}$ remained stable and $\mathrm{Pa}, \mathrm{CO}_{2}$ increased slightly. These results are difficult to interpret for two reasons. Firstly, arterial blood gases evolved in a divergent way in these patients. Indeed, 17 patients exhibited concomitant improvement in $\mathrm{Pa}, \mathrm{O}_{2}$ and $\mathrm{Pa}, \mathrm{CO}_{2}$ and 27 exhibited concomitant worsening. On the other hand, $\mathrm{Pa}, \mathrm{O}_{2}$ and $\mathrm{Pa}, \mathrm{CO}_{2}$ increased or decreased concomitantly in 21 patients. Secondly, we did not investigate the ventilatory drive in these patients and measurement of alveolar ventilation and alveolar-arterial partial pressure of oxygen difference were only available in a few patients, respectively. Several reports $[4,17,18]$ have shown a decrease of $P \mathrm{a}, \mathrm{CO}_{2}$ after long-term use of nasal CPAP in OSAS patients, associated with an increase of ventilatory drive. It should, however, be kept in mind that these reports included a high percentage of severely obese patients; this was not the case of the present study, which is probably more representative of the "general" population of OSAS patients in Europe. As mentioned by KozIEJ et al. [19] the decrease of $\mathrm{Pa}_{2} \mathrm{CO}_{2}$ after treatment with nasal CPAP is not observed in OSAS patients with associated COPD, and the 65 patients of the present study included a high percentage of such "overlap" patients.

The present data also show that in patients who were hypoxaemic at $t 0, \mathrm{~Pa}_{\mathrm{a}} \mathrm{O}_{2}$ increased. Since $\mathrm{Pa}, \mathrm{O}_{2}$ did not increase in the group as a whole, this improvement could be due to regression to the mean. Importantly, however, it is clear that these more severely hypoxaemic patients did not deteriorate when treated with nasal CPAP.

As regards pulmonary haemodynamics we believe that the group of 44 patients in whom $\bar{P}$ pa could be reevaluated is representative of the group as a whole. Indeed, as mentioned above, there were no differences in terms of all variables at $t 0$ between these patients and the remainder. In these 44 patients we observed that $\bar{P}_{\text {pa }}$ at rest and during exercise remained unchanged at the follow-up evaluation. FLENLEY [20] first suggested that nocturnal events could potentiate the pulmonary vascular effects of lung disease in the "overlap syndrome". In a recent study [21] we observed that 37 OSAS patients with pulmonary hypertension diagnosed before starting specific treatment had a mean daytime $\mathrm{Pa}_{\mathrm{a}} \mathrm{O}_{2}$ of $8.5 \pm 1.2 \mathrm{kPa}(64 \pm 9 \mathrm{mmHg})$, whereas pulmonary hypertension in COPD patients generally occurs with a lower $\mathrm{Pa}, \mathrm{O}_{2}$, usually $<7.3 \mathrm{kPa}(55 \mathrm{mmHg})$. This discordance has been emphasized by several groups [9, 22, 23]. It is probably the result of transient nocturnal hypoxaemia and pulmonary hypertensive peaks. Accordingly one may suppose that suppressing nocturnal events with nasal CPAP in these patients has prevented further increases of $\bar{P}$ pa, particularly in those who had the highest daytime $\bar{P}_{\text {pa at }}$ at onset of the study.

We conclude that the significant decrease of forced expiratory volume in one second after 5 yr follow-up was related to a high percentage of smokers and exsmokers in our population. Daytime arterial oxygen tension and pulmonary artery pressure remained stable in an unselected series of 65 obstructive sleep apnoea syndrome patients treated for 5 yrs with nasal continuous positive airway pressure. This was particularly noteworthy in patients who showed the most abnormal values at the start of the study.

\section{References}

1. Sullivan CE, Issa FG, Berthon-Jones M, Eves L. Reversal of obstructive sleep apnoea by continuous positive airway pressure applied through the nares. Lancet 1981; 1: $862-865$.

2. Sforza E, Krieger J, Weitzenblum E, Apprill M, Lampert E, Ratamaharo E. Long-term effects of treatment with nasal continuous positive airway pressure on daytime lung function and pulmonary hemodynamics in patients 
with obstructive sleep apnea. Am Rev Respir Dis 1990; 141: 866-870.

3. Young IH, Mihalyka M, Costas L, Sullivan CE. Longterm lung function changes in patients with obstructive sleep apnea during treatment with nasal continuous positive airway pressure. Thorax 1987; 42: 722.

4. Leech JA, Önal E, Lopata M. Nasal CPAP continues to improve sleep-disordered breathing and daytime oxygenation over long-term follow-up of occlusive sleep apnea syndrome. Chest 1992; 102: 1651-1655.

5. Guilleminault C, Tilkian A, Dement WC. The sleep apnea syndromes. Ann Rev Med 1976; 27: 465-484.

6. Quanjer PH, Tammeling GJ, Cotes JE, Pedersen OF, Peslin R, Yernault JC. Lung volumes and forced ventilatory flows. Eur Respir J 1993; 6 (Suppl. 16): 15-40.

7. Weitzenblum E, Loiseau A, Hirth C, Mirhom R, Rasaholinjanahary J. Course of pulmonary hemodynamics in patients with chronic obstructive pulmonary disease. Chest 1979; 75: 656-662.

8. Le Floch JP, Perlemuter L. Types et phases d'une étude. In: Essais thérapeutiques et études cliniques. Paris, Masson, 1995; pp. 31-32.

9. Bradley TD, Rutherford A, Grossmann RF, et al. Role of daytime hypoxemia in the pathogenesis of right heart failure in the obstructive sleep apnea syndrome. Am Rev Respir Dis 1985; 131: 835-839.

10. Podszus T, Bauer W, Mayer J, Penzel T, Peter JH, Von Wichert P. Sleep apnea and pulmonary hypertension. Klin Woschenschr 1986; 64: 131-134.

11. Fletcher CM. Causes and development of chronic airways obstruction and its further investigation. Bull Physiopath Respir 1973; 9: 1131-1148.

12. Snider GL, Failing J, Rennard SI. Chronic bronchitis and emphysema. In: Murray JF, Nadel A, eds. Textbook of Respiratory Medicine. Philadelphia, WB Saunders, 1994; pp. 1335-1348.

13. Burrows B. The course and prognosis of different types of chronic airflow limitation in a general population sample from Arizona: comparison with the Chicago "COPD" series. Am Rev Respir Dis 1989; 140: S92-S94.

14. Wetter DW, Young BT, Bidwell TR, Badr MS, Palta M. Smoking as a risk factor for sleep disordered breathing. Arch Intern Med 1994; 154: 2219-2224.

15. Chaouat A, Weitzenblum E, Krieger J, Ifoundza Th, Oswald M, Kessler R. Association of chronic obstructive pulmonary disease and sleep apnea syndrome. Am J Respir Crit Care Med 1995; 151: 82-86.

16. Bradley TD, Rutherford A, Lue F, et al. Role of diffuse airway obstruction in the hypercapnia of obstructive apnea. Am Rev Respir Dis 1986; 134: 920-924.

17. Berthon-Jones M, Sullivan CE. Time course of change in ventilatory response to $\mathrm{CO}_{2}$ with long-term CPAP therapy for obstructive sleep apnea. Am Rev Respir Dis 1987; 135: 144-147.

18. Lin CC. Effect of nasal CPAP on ventilatory drive in normocapnic and hypercapnic patients with obstructive sleep apnea syndrome. Eur Respir J 1994; 7: 2005-2010.

19. Koziej M, Zielinski J, Radwan L. Control of breathing in hypercapnic patients with obstructive sleep apnoea. Eur Respir J 1996; 9: 1576-1577.

20. Flenley DC. Sleep in chronic obstructive lung disease. Clin Chest Med 1985; 6: 51-61.

21. Chaouat A, Weitzenblum E, Krieger J, Oswald M, Kessler R. Pulmonary hemodynamics in the obstructive sleep apnea syndrome: results in 220 consecutive patients. Chest 1996; 109: 380-386.

22. Hawrylkiewicz I, Cieslicki J, Palasiewicz G, Zielinski $\mathrm{J}$ Pulmonary haemodynamics at rest and on exercise in patients with obstructive sleep apnoea (OSA). Eur Respir J 1992; 5: Suppl 15, 164s-165s.

23. Fletcher EC, Schaef JM, Miller J, Fletcher JG. Long-term cardiopulmonary sequelae in patients with sleep apnea and chronic lung disease. Am Rev Respir Dis 1987; 135: 525-533. 